\title{
ANTIOXIDANT ACTIVITY OF SELECTED WILD CANADIAN PRAIRIE FRUITS*
}

\author{
Dorota Klensporf-Pawlik ${ }^{1 \bowtie}$, Roman Przybylski² \\ ${ }^{1}$ Department of Food Commodity Science, Poznań University of Economics \\ Niepodległości 10, 61-875 Poznań, Poland \\ 2Department of Chemistry and Biochemistry, University of Lethbridge \\ 4401 University Drive West Lethbridge, AB T1K 3M4, Canada
}

\begin{abstract}
Background. Canadian prairies are a habitat for unique wild plants. The main object of the present study was to investigate phytochemicals content and antioxidant activity in seven wild Canadian prairie fruits.

Material and methods. The presence of total phenolics, flavonoids, anthocyanins and antioxidant activity were identified in the extracts according to standard procedure.

Results. Wild rose had the highest amounts of total phenolics and total flavonoids, whereas elderberry exhibited the highest amount of anthocyanins. All extracts showed good scavenging activities towards DPPH radicals. The results showed a good linear relationship between oxygen radical absorbance capacity and total phenolics indicating that radicals are scavenged at a greater rate as the total phenolics content increases. Additionally, all extracts when applied at concentration of $800 \mathrm{ppm}$, showed ability to inhibit oxidation of canola oil. In SOT test the best results were obtained when extract of American mountain ash was used. In general, wild rose followed by American mountain ash demonstrated the highest antioxidant activity among assessed Canadian prairie fruits.

Conclusion. From the results it can be concluded that prairie fruit extracts are a rich source of phenolic compounds and poses a high antioxidant activity, confirmed by assessment with different type of radicals employed.
\end{abstract}

Key words: phenolics, natural antioxidants, antioxidant activity, Canadian prairie fruits, anthocyanins, flavonoids

\section{INTRODUCTION}

Plants produce significant amount of antioxidants to prevent the oxidative stress caused by light and oxygen, forming a potential source of new compounds with high antioxidant activity. The phytochemicals in plant tissues responsible for the antioxidant capacity can largely be attributed to phenolic compounds mainly flavonoids (Cao et al., 1997). The utilization of plant bioactive components may increase the stability of foods and, at the same time, these components may have positive health outcome (Rice-Evans et al., 1996). Crude extracts from fruits, herbs, cereals and other plant materials rich in phenolics are of food industry interest because of their positive health impact and concerns over the safety of synthetic antioxidants

\footnotetext{
*This work is a part of research financially supported by Alberta Value Added Corporation and Agriculture Funding Consortium.

『dorota.klensporf-pawlik@ue.poznan.pl
} 
(Loliger, 1991). Phenolic compounds have been considered powerful antioxidants in vitro (Frankel et al., 1995; Villano et al., 2005) and have been proved to be more effective than vitamins $\mathrm{C}, \mathrm{E}$ and glutathione as measured by scavenging of peroxyl radicals (Cao et al., 1993). Phenolic compounds play a key role as antioxidants because hydroxyl substituents on their aromatic structure easily donating hydrogen and scavenge free radicals (Verhagen et al., 1996). However, their antioxidant activity is dependent on the arrangement of hydroxyl and methoxy groups, composition and concentration (Rice-Evans et al., 1997; Wanasundara and Shahidi, 1998; Abuja et al., 1998). Natural antioxidants function as free radical scavengers, chain breakers, metal chelators and quenchers of singlet-oxygen (Pratt, 1992). Phenolics may also act as a prooxidant at specific conditions, stimulating oxidative damage to biological targets (Cao et al., 1997; Abuja et al., 1998).

Many North American native fruits offer unusual medicinal and nutritional properties (Acuna et al., 2002; Anwar et al., 2008). Moreover, the Canadian prairies have a wealth of untapped plant species which could be used as a source of nutraceutical food ingredients (Amarowicz et al., 2004). Western Canada berries, name the few: bilberries, lingonberries, crowberries, bunchberries, red, black and purple raspberries are recognized as an excellent source of bioactive compounds such as anthocyanins, phenolic acids and flavonoids (Bakowska-Barczak et al., 2007). Saskatoon berries are a rich source of phenolics, mostly proanthocyanins and flavonols, but the amount is highly dependent on the cultivar (Bakowska-Barczak and Kolodziejczyk, 2008; Hosseinian et al., 2007). Native rose, Rosa sp., from British Columbia revealed antioxidant and antimicrobial activity which was highly correlated with total amount of phenolics (Yi et al., 2007).

Finding alternative food antioxidant sources, especially from natural products, that may have the potential to provide additional health benefits is desired. Therefore, the purpose of our study was to investigate the phytochemicals and antioxidant activity of several Canadian prairie wild fruits, namely: chokecherry, silver buffaloberry, hawthorn, woods' rose, elderberry, European rowan and American mountain ash.

\section{MATERIAL AND METHODS}

\section{Materials}

Fully ripened fruits of: chokecherry (CC) (Prunus virginiana), silver buffaloberry (BB) (Shepherdia argentea), hawthorn (HA) (Crataegus mordenensis), woods' rose (RW) (Rosa woodsii), elderberry (EB) (Sambucus cerulea), European rowan (ER) (Sorbus aucuparia) were collected in the Oldman River Valley in Southern Alberta while American mountain ash (AMA) (Sorbus americana) in the Waterton Lakes area. Abbreviation for following fruit name is used in the text.

Cyanidin-3-rutinoside was purchased from Chromadex (Irvine, CA). Gallic acid, catechin, DPPH, TROLOX, AAPH, Folin-Ciocalteu's phenol reagent, ferrous chloride and Tween 40 were purchased from Sigma-Aldrich Chemical Co. (St. Louis, USA). Fluorescein, linoleic acid and b-carotene were obtained from Fluka (Steinheim, Germany); anhydrous ferric chloride from Riedel-de Haen (Steinheim, Germany) and ammonium thiocyanate, sodium hydroxide and sodium nitrite from Baker Analyzed (Phillipsburg, USA). Aluminium chloride, hydrochloric acid, phosphate buffer and chloroform obtained from Thermo Fisher Scientific (Edmonton, Canada); sodium carbonate Amachem (Portland, USA); methanol from EMD Chemicals (Darmstadt, Germany) while propylene glycol from Alfa Aesar (Ward Hill, USA).

\section{Preparation of extract}

Plant material was ground and $20 \mathrm{~g}$ used for double extraction with $100 \mathrm{~mL}$ of $80 \%$ methanol. Sample was mixed for $1.5 \mathrm{hrs}$ at room temperature. Extracts were filtered and concentrated to $100 \mathrm{~mL}$ under vacuum using a rotary evaporator. The concentrated extracts were stored at $-20^{\circ} \mathrm{C}$ until analysed. The yield of extract were expressed as weight ( $\mathrm{g}$ ) of crude extract per $100 \mathrm{~g}$ of fresh plant material.

\section{Determination of total phenolics}

The amount of total phenolics was measured by Folin-Ciocalteu procedure following Skerget et al. (2005) with modification. Briefly, to $0.5 \mathrm{~mL}$ of diluted extract, $2.5 \mathrm{~mL}$ of Folin-Ciocalteu reagent $(0.2 \mathrm{~N}$ in water) and $2 \mathrm{~mL}$ of $\mathrm{Na}_{2} \mathrm{CO}_{3}(75 \mathrm{~g} / \mathrm{L})$ were added and incubated for $5 \mathrm{~min}$ at $50^{\circ} \mathrm{C}$. Distilled water was used as a reference. The absorbance was measured at $760 \mathrm{~nm}$ 
and results expressed as gallic acid equivalents per dry mass of extract (mg GAE/g DM). All analyses were performed in triplicate.

\section{Determination of total flavonoids}

The amount of flavonoids was determined following procedure described by Dewanto et al. (2002). One $\mathrm{mL}$ of diluted extract was placed in a $10 \mathrm{~mL}$ volumetric flask then $5 \mathrm{~mL}$ of distilled water and $0.3 \mathrm{~mL}$ of $5 \%$ $\mathrm{NaNO}_{2}$ were added. After 5 min of mixing, $0.6 \mathrm{~mL}$ of $10 \% \mathrm{AlCl}_{3}$ was added and continued mixing for $5 \mathrm{~min}$ followed by $2 \mathrm{~mL}$ of $1 \mathrm{M} \mathrm{NaOH}$ and the volume made up with distilled water. The absorbance was measured at $510 \mathrm{~nm}$. The total flavonoid content is expressed as catechin equivalents per dry mass of extract ( $\mathrm{mg} \mathrm{CE} / \mathrm{g}$ DM). All analyses were performed in triplicate.

\section{Determination of total anthocyanins}

Total anthocyanins content was assessed following the procedure described by Lohachoompol et al. (2004). Extracts were diluted with mixture of methanol and $0.1 \mathrm{M} \mathrm{HCl}(85: 15 \mathrm{v} / \mathrm{v})$ and incubated for 5 minutes at room temperature then absorbance measured at $538 \mathrm{~nm}$. Cyanidin-3-rutinoside was used for calibration and the total amount of anthocyanins is expressed as cyanidin3-rutinoside equivalents per dry mass of extract (mg CRE/g DM). All analyses were performed in triplicate.

\section{Identification of phenolics by HPLC-ESI-MS/MS}

The HPLC-ESI-MS/MS analyses were performed using a 1100 Series Agilent Technologies LC/MSD system equipped with a diode array detector coupled to a quadrupole mass spectrometer with an ESI interface (Agilent Technologies, Mississagua, Ont.). The reverse-phase separation was performed on a Vydac C18 column $(5 \mu \mathrm{m} ; 250 \mathrm{~mm} \times 4.6 \mathrm{~mm}$; Grace, Hespedia, CA.). The compounds were separated using eluent (A): $4.5 \%$ aqueous formic acid and eluent (B): acetonitrile diluted to $80 \%$ with $4.5 \%$ formic acid in water. The gradient was as follows: $7 \mathrm{~min} 15 \% \mathrm{~B} ; 15$ $\min 20 \% \mathrm{~B} ; 16 \min 100 \% \mathrm{~B}$ and in 24 min returned to $100 \%$ of eluent A. MS parameters were as follows: capillary voltage $4000 \mathrm{~V}$; drying gas temperature $350^{\circ} \mathrm{C}$; nitrogen flow $12 \mathrm{~L} / \mathrm{min}$; nebulizer pressure 60 psi. The instrument was scanned positive and negative ions in the range from 100 to $1500 \mathrm{~m} / \mathrm{z}$ at a rate of $2.0 \mathrm{~s} /$ cycle. Compounds identification is based on spectra library developed in laboratory and published data (Gil-Izquierdo and Mallenthin, 2001).

\section{Evaluation of antioxidant potential}

Antioxidative activity of the prairie fruits were evaluated using the following methods: (1) scavenging 2,2-diphenyl-1-picrylhydrazyl (DPPH) free radical, (2) oxygen radical absorbance capacity (ORAC), (3) $\beta$-carotene bleaching in linoleic acid emulsion and (4) Schaal oven test (SOT) using canola oil.

\section{DPPH free radical scavenging activity}

Radical scavenging activity was assessed following procedure described by Sanchez-Moreno et al. (1998). Briefly, $0.1 \mathrm{~mL}$ of methanolic solution of extract at five different concentrations was added to $3.9 \mathrm{~mL}$ of 0.06 $\mathrm{mM}$ DPPH in methanol. The decrease in absorbance was measured at $515 \mathrm{~nm}$ until the reaction reached equilibrium. Reaction kinetics of extracts with DPPH was registered for each concentration of extract tested. Percentage of DPPH remaining at steady state was calculated from the following equation:

$$
\% \mathrm{DPPH}_{\mathrm{rem}}=\left(\mathrm{A}_{\mathrm{I}} / \mathrm{A}_{0}\right) \times 100
$$

where:

$\mathrm{A}_{0}, \mathrm{~A}_{\mathrm{T}}$ - is the absorbance at the beginning and at the steady state.

Concentration of extracts were plotted against the remaining $\%$ of DPPH at the steady state to obtain the half-life $\left(\mathrm{EC}_{50}\right)$ of DPPH radicals, which is defined as an amount of antioxidant needed to decrease the initial DPPH concentration by $50 \%$. Time needed to reach the steady state at $\mathrm{EC}_{50}$ concentration of extract $\left(\mathrm{TEC}_{50}\right)$ was also calculated graphically. Scavenging efficiency (SE) of tested extracts was calculated from the following equation:

$$
\mathrm{SE}=1 /\left(\mathrm{EC}_{50} \times \mathrm{TEC}_{50}\right)
$$

\section{Oxygen Radical Absorbance Capacity (ORAC)}

ORAC assays were conducted as described by Szydłowska-Czerniak et al. (2008) using Cary Eclipse fluorescence spectrophotometer equipped with a temperature controlled sample holder (Varian, Canada). The reaction mixture contains: $3 \mathrm{~mL}$ of $0.0816 \mathrm{mmol} / \mathrm{L}$ fluorescein dissolve in $0.075 \mathrm{~mol} / \mathrm{L}$ phosphate buffer ( $\mathrm{pH}=7.4) ; 0.5 \mathrm{~mL}$ of extracts diluted to $50 \mathrm{mg} / \mathrm{mL}$ 
whereas wild rose extract was diluted to $5 \mathrm{mg} / \mathrm{mL}$. Calibration was done with $0.5 \mathrm{~mL}$ of Trolox solution at concentrations of 12.5 to $125 \mathrm{mmol} / \mathrm{L}$. Reference sample contained phosphate buffer in place of extract. Mixture was kept for $10 \mathrm{~min}$ at $37^{\circ} \mathrm{C}$ in the dark, and the reaction was initiated when $0.5 \mathrm{~mL}$ of $153 \mathrm{mmol} / \mathrm{L}$ AAPH was added. The fluorescence decay was measured at $37^{\circ} \mathrm{C}$ every $30 \mathrm{~s}$ for $40 \mathrm{~min}$ using emission at $525 \mathrm{~nm}$ and excitation at $485 \mathrm{~nm}$. A calibration curve was generated using the net area under fluorescein decay curve in the presence of five concentrations of Trolox, using the following equation for calculation:

$$
\mathrm{AUC}_{\mathrm{n}}=\mathrm{AUC}_{\mathrm{s}}-\mathrm{AUC}_{\mathrm{b}}
$$

where:

$\mathrm{AUC}_{\mathrm{n}, \mathrm{s}, \mathrm{b}}-$ net, sample (standard) and blank decay curve area.

Data are expressed as mmol of Trolox equivalents per dry mass of extract (mmol TE/g DM).

\section{$\beta$-Carotene bleaching in linoleic acid emulsion system}

$\beta$-Carotene solution in chloroform $(1 \mathrm{mg} / 10 \mathrm{~mL})$ was added to a flask containing $20 \mathrm{mg}$ of linoleic acid and $200 \mathrm{mg}$ of Tween 40 . The chloroform was removed under vacuum at $45^{\circ} \mathrm{C}$ using rotary evaporator. To a semi solid residue $50 \mathrm{~mL}$ of distilled water was slowly added and vigorously agitated to form an emulsion (Taga et al., 1984). A $0.2 \mathrm{~mL}$ of the diluted extract $(3 \mathrm{mg} / \mathrm{mL})$ was mixed with $5 \mathrm{~mL}$ of prepared emulsion and the absorbance measured immediately at $470 \mathrm{~nm}$, against blank without $\beta$-carotene. Samples were incubated at $50^{\circ} \mathrm{C}$ in a water bath, and absorbance monitored after 60 and $120 \mathrm{~min}$. The antioxidant activity was calculated using the following equation:

$$
\mathrm{AA}=\left[1-\left(\mathrm{A}_{\mathrm{s}}-\mathrm{A}_{\mathrm{si}}\right) /\left(\mathrm{A}_{\mathrm{c}}-\mathrm{A}_{\mathrm{ci}}\right)\right] \times 100
$$

where:

$A_{c}, A_{s}$ - the absorbance measured at "time zero", $\mathrm{A}_{\mathrm{ci}}, \mathrm{A}_{\mathrm{si}}$ - the absorbance measured after incubation in control and analysed sample, respectively.

\section{Schaal Oven Test}

To solubilize fruit extracts in canola oil propylene glycol was used as carrier solvent and extracts were added to obtain final concentration $800 \mathrm{ppm}$. Oil samples with fruit extracts and control with the same volume of propylene glycol were stored in dark for 6 days at $65^{\circ} \mathrm{C}$, keeping ratio between surface area and volume at 0.8 . Peroxide value was measured daily utilizing colorimetric procedure described by Shantha and Decker (1994). Briefly, $25 \mathrm{mg}$ of oil was mixed with $9.8 \mathrm{~mL}$ chloroform-methanol $(7: 3 \mathrm{v} / \mathrm{v})$, then $50 \mathrm{~mL}$ of ferrous solution was added, and sample mixed and incubated for $5 \mathrm{~min}$ at room temperature. After incubation, $50 \mathrm{~mL}$ of ammonium thiocyanate solution $(30 \mathrm{~g} / 100 \mathrm{~mL})$ was added and sample again incubated for $5 \mathrm{~min}$ at ambient temperature followed by absorbance measured at $500 \mathrm{~nm}$. Peroxide value was calculated using the following equation:

$$
\mathrm{PV}(\mathrm{meq} / \mathrm{kg})=\left(\mathrm{A}_{\mathrm{s}}-\mathrm{A}_{\mathrm{bl}}\right) /\left(55.84 \times 2 \times \mathrm{m} \times \mathrm{W}_{\mathrm{s}}\right)
$$

where:

$\mathrm{A}_{\mathrm{s}}$ - the absorbance of the sample,

$\mathrm{A}_{\mathrm{bl}}$ - the absorbance of the blank,

$\mathrm{m}$ - the slope of the calibration curve: 55.84 is atomic weight of iron: 2 is a factor to convert meq of $\mathrm{Fe}$ to meq of peroxide,

$\mathrm{W}_{\mathrm{s}}$ - the sample weight, $\mathrm{g}$.

\section{Statistical analysis}

One-way analysis of variance (ANOVA) was applied, a post-hoc test (Duncan) was used to determine differences in means, where applicable (Statistica 10.0, StatSoft, Tulsa, USA).

\section{RESULTS AND DISCUSSION}

\section{Phenolics, flavonoids and anthocyanins}

Extraction with the same solvent of all fruits bestowed different amounts of compounds extracted; EB and ER provided the highest yield of extracts (Table 1). Total phenolics content varied greatly among analysed fruits, ranging from 39.6 to $656.4 \mathrm{mg} \mathrm{GAE} / \mathrm{g} \mathrm{DM}$ (Table 1). The highest amount of phenolics was found in RW samples, whereas ER samples had the lowest. American mountain ash contained four times more phenolics than European rowan, both belongs to the same genus however form different cultivars and are growing at different conditions. The former was collected at altitude above $2000 \mathrm{~m}$ where growing conditions are much harsher, causing that plant will produce more phenolic components when under stress (Kirakosyan et al., 2003). Rowan berries are known to have 
Table 1. Content of total phenolics, flavonoids, and anthocyanins in Canadian prairie fruits

\begin{tabular}{ccccc}
\hline Prairie fruit & $\begin{array}{c}\text { Phenolics } \\
\text { mg GEA/g* }\end{array}$ & $\begin{array}{c}\text { Flavonoids } \\
\text { mg CE/g* }\end{array}$ & $\begin{array}{c}\text { Anthocyanins } \\
\text { mg CRE/g* }\end{array}$ & $\begin{array}{c}\text { Extract yield** } \\
\text { g/100 g fresh }\end{array}$ \\
\hline CC & $114.9 \pm 1.2^{\mathrm{c}}$ & $30.9 \pm 1.4^{\mathrm{c}}$ & $16.0 \pm 1.0^{\mathrm{b}}$ & $17.2 \pm 1$ \\
BB & $100.9 \pm 2.0^{\mathrm{c}}$ & $26.3 \pm 0.3^{\mathrm{d}}$ & $0.1 \pm 0^{\mathrm{e}}$ & $17.9 \pm 1$ \\
AMA & $154.8 \pm 3.3^{\mathrm{b}}$ & $50.4 \pm 1.5^{\mathrm{b}}$ & $1.7 \pm 0.2^{\mathrm{d}}$ & $20.7 \pm 2$ \\
EB & $141.9 \pm 3.3^{\mathrm{b}}$ & $17.7 \pm 0.8^{\mathrm{e}}$ & $42.0 \pm 1.7^{\mathrm{a}}$ & $43.9 \pm 2$ \\
ER & $39.6 \pm 1.4^{\mathrm{d}}$ & $13.6 \pm 0.7^{\mathrm{e}}$ & $0.3 \pm 0^{\mathrm{e}, \mathrm{d}}$ & $34.5 \pm 2$ \\
HA & $103.1 \pm 2.8^{\mathrm{c}}$ & $28.5 \pm 1.0^{\mathrm{c}, \mathrm{d}}$ & $5.7 \pm 0.4^{\mathrm{c}}$ & $14.9 \pm 1$ \\
RW & $656.4 \pm 26.2^{\mathrm{a}}$ & $149.4 \pm 5.8^{\mathrm{a}}$ & $0.3 \pm 0^{\mathrm{e}, \mathrm{d}}$ & $17.4 \pm 2$ \\
\hline
\end{tabular}

Values in the same column with different superscripts differ at $P<0.05$.

Values are reported as mean $\pm \mathrm{SD}$ from triplicate determination.

CC - chokecherry, BB - silver buffaloberry, AMA - American mountain ash, ER - European rowan, EB - elderberry, HA - hawthorn, RW - woods' rose (wild rose).

*Data expressed as mg equivalents of: GAE - gallic acid, CE - catechin, CRE - cyanidin-3-ruti-

noside per $g$ of dry matter.

**Weight $(\mathrm{g})$ of crude extract per $100 \mathrm{~g}$ of fresh plant material.

high concentration of phenolics; however its content is affected by a cultivar and growing conditions and may vary from 550 to $1014 \mathrm{mg} / 100 \mathrm{~g}$ of fresh weight (Hukkanen et al, 2006; Kahkonen et al., 2001).

Prairie fruits with high total phenolics content also had higher amounts of total flavonoids (Table 1). In AMA and ER extracts total flavonoid contributed more than $30 \%$ of the total phenolic compounds, while in EB only $12 \%$. In hawthorn fruits which are recognized as a rich source of flavonoids (Cao et al., 1995) the total amount was at $28.5 \mathrm{mg} \mathrm{CE} / \mathrm{g} \mathrm{DM}$, which is $28 \%$ of total phenolics. Similar contribution of flavonoids amongst phenolics was observed in chokecherry and buffaloberry extracts (Table 1).

Among analysed fruits, only elderberry and chokecherry extracts were very dark in colour, indicating a high proportion of anthocyanins, known as natural pigments responsible for blue, purple, violet and red colors in fruits (Wu et al., 2004). Total anthocyanins content expressed as cyanidin-3-rutinoside equivalents was at 42 and $16 \mathrm{mg} \mathrm{CRE} / \mathrm{g}$ of DM in discussed fruits, respectively (Table 1). Sums of the total amounts of flavonoids and anthocyanins accounted for $23 \%$ in RW and $42 \%$ in EB of total phenolics. Although, wild rose had the highest amount of total phenolics, the contribution of TF and TA was much lower than in other extracts. This high amount of phenolics can be related to the presence of ascorbic acid, which in wild rose fruits usually is present in the higher amounts than found even in citrus fruits (Ercisli and Esitken, 2004). Quantification of total phenolics using FolinCiocalteau reagent is based on the redox reactions, therefore non-phenolic compounds like vitamin $\mathrm{C}$ could contribute and interfere with assessment (Huang et al., 2005).

Most of phenolic compounds was identified and relatively quantified by HPLC-MS and the data in Table 2 are included. The phenolics profiles of all fruits extracts revealed that anthocyanins contributed in majority with exception of BB and RW where rutin was the main component (Table 2). The anthocyanin profile was similar in all prairie fruits, but the proportions of each compound were varying. Rowan and Mountain ash contained the widest range of cyanidins (Table 2). Cyanidin-3-arabinoside was found as the main compound in American mountain ash and rowan fruits, accounted for 51 and $42 \%$ of total peak area, respectively. Additionally, both fruits had high proportion of rutin (Table 2). Among analysed fruits, cyanidin-3-glucoside was the main compound in elderberry and hawthorn. These results stays in agreement with data reported by Bronnum-Hansen and Hansen (1983) 

ment., 14(4), 357-366. DOI: 10.17306/J.AFS.2015.4.35

Table 2. Composition of phenolic compounds in prairie fruits, $\%$

\begin{tabular}{|c|c|c|c|c|c|c|c|}
\hline Phenolics & $\mathrm{CC}$ & $\mathrm{BB}$ & HA & RW & EB & ER & AMA \\
\hline Cyanidin-3-glucoside & 16.5 & 5.6 & 74.2 & 2.4 & 62 & 2.8 & 1.5 \\
\hline Cyanidin-3-rutinoside & 77.5 & & & 3.9 & & 2.6 & \\
\hline Cyanidin-3-galactoside & 1.7 & & 2.4 & & & 2.2 & 1.8 \\
\hline Cyanidin-3-arabinoside & 1 & 4.8 & 1.9 & & & 42.3 & 51.1 \\
\hline Cyanidin-3-xyloside & & 14.6 & 2.6 & 5.9 & & 3.6 & 5.9 \\
\hline Cyanidin-3,5-diglucoside & & & & & 3.7 & 7.6 & 8.7 \\
\hline Pelargonidin-3-glucoside & & 3.6 & 8.8 & & & 4.2 & 3.1 \\
\hline Quercetin-3-glucoside & & & 2.1 & 2.2 & & 3.1 & 1.8 \\
\hline Quercetin-pentoside & & & & 4.2 & & 1.8 & \\
\hline Rutin & 2.2 & 66.9 & 5.4 & 74.5 & 2.2 & 26.4 & 23.3 \\
\hline Cyanidin-3-sambubioside & & & & & 30 & & \\
\hline Cyanidin-3-sambubioside-5-glucoside & & & & & 2.1 & & \\
\hline Delphinidin-3-glucoside & 1.1 & 4.5 & 2.6 & & & 3.4 & 2.8 \\
\hline Petunidin-3-glucoside & & & & 6.9 & & & \\
\hline
\end{tabular}

For sample abbreviation see Table 1.

and $\mathrm{Wu}$ and Prior (2005). Moreover, in elderberry fruits cyanidin-3-sambubioside was also identified as the second most abundant compound. Both identified anthocyanins accounted for over $90 \%$ of total peak area in elderberry fruits. However, Wu et al. (2004) detected seven anthocyanins in elderberry (Sambucus nigra), among which were pelargonidin derivatives, identified in elderberry for the first time. In our studies, the main anthocyanin presented in chokecherries was cyanidin-3-rutinoside (77.5\% of total peak area), which was also among 9 anthocyanin which are colouring compounds identified by Bakowska-Barczak et al. (2007). Additionally, Wu and Prior (2005) established that cyanidin-3-rutinoside is the main compound in fruits belonging to Prunus genus.

\section{Antioxidant potential}

The free radical scavenging activity of prairie fruit extracts expressed as scavenging efficiency (SE) in Table 3 is shown. All extracts showed significant DPPH radicals scavenging activity, reaching up to $93 \%$ for RW extract at concentration $0.175 \mathrm{mg} / \mathrm{mL}$ and achieving $\mathrm{EC}_{50}$ at concentration of $0.05 \mathrm{mg} / \mathrm{mL}$. The highest $\mathrm{EC}_{50}$ of $2.63 \mathrm{mg} / \mathrm{mL}$ was found for ER extracts, indicating the lowest antioxidant activity among all analysed samples, showing also the lowest scavenging efficiency (SE) at $2.38 \times 10^{-3}$ (Table 3). Among all extract RW offered the highest scavenging efficiency (SE) multiple times higher than other extracts (Table 3).

$\mathrm{EC}_{50}$ is inversely related to the antioxidant capacity of a compound or extract, the lower $\mathrm{EC}_{50}$ the higher the antioxidant activity of compounds in extract. Time required to achieve the steady state in DPPH scavenging describes the rate at which antioxidants scavenged radicals (Sanchez-Moreno et al., 1998). On the bases of time needed to reach the steady state for $\mathrm{EC}_{50}$ all extracts belong to slow antioxidants, the $\mathrm{TEC}_{50}$ differed among samples from $63 \mathrm{~min}$ for chokecherry to 160 min for European rowan (Table 3). Although, $\mathrm{EC}_{50}$ for hawthorn was similar to that determined for chokecherry (1.30 and $1.15 \mathrm{mg} / \mathrm{mL}$, respectively), its antioxidant efficiency was over two folds lower, because of much longer time needed to reach the steady state 
Table 3. Radical scavenging and oxygen radical absorbance capacity of Canadian prairie fruits

\begin{tabular}{ccccc}
\hline Prairie fruit & $\mathrm{EC}_{50}, \mathrm{mg} / \mathrm{mL}$ & $\mathrm{TEC}_{50}, \mathrm{~min}$ & $\mathrm{SE}\left(\times 10^{-3}\right)$ & ORAC, mM TE/g \\
\hline $\mathrm{CC}$ & $1.2 \pm 0.08$ & $63 \pm 3$ & $13.8 \pm 0.96$ & $0.66 \pm 0.03$ \\
$\mathrm{BB}$ & $1.8 \pm 0.13$ & $107 \pm 5$ & $5.2 \pm 0.36$ & $0.37 \pm 0.01$ \\
AMA & $0.9 \pm 0.06$ & $114 \pm 6$ & $10.3 \pm 0.72$ & $1.06 \pm 0.04$ \\
EB & $2.2 \pm 0.16$ & $88 \pm 4$ & $5.1 \pm 0.36$ & $1.31 \pm 0.05$ \\
ER & $2.6 \pm 0.18$ & $160 \pm 8$ & $2.4 \pm 0.17$ & $0.16 \pm 0.01$ \\
$\mathrm{HA}$ & $1.3 \pm 0.09$ & $128 \pm 7$ & $6.0 \pm 0.42$ & $1.03 \pm 0.04$ \\
$\mathrm{RW}$ & $0.1 \pm 0.03$ & $103 \pm 5$ & $210 \pm 15$ & $7.99 \pm 0.31$ \\
\hline
\end{tabular}

Values are reported as mean \pm SD from triplicate determination.

$\mathrm{EC}_{50}$ - amount of antioxidant needed to decrease the initial DPPH concentration by $50 \%, \mathrm{TEC}_{50}-$ time needed to reach the steady state for DPPH at $\mathrm{EC}_{50}$ concentration, $\mathrm{SE}$ - scavenging efficiency, ORAC - oxygen radical absorbance capacity (data expressed per g of extract dry matter).

For sample abbreviation see Table 1.

(Table 3). Tadic et al. (2008) reported radical scavenging activity of ethanol extract prepared from hawthorn in the range from 90 to $40 \%$, and the $\mathrm{EC}_{50}$ value at 1.47 $\mathrm{mg} / \mathrm{mL}$. It was also shown that hawthorn flavonoids are mainly responsible for radical scavenging capacity in this fruit (Chu et al., 2003). In our study, higher regression coefficient was observed for the relation between scavenging activity and total flavonoids content than for total phenolics content, $R^{2}=0.80$ vs. 0.68 , respectively (data not shown). Additionally, these results confirmed that radical scavenging activity of the prairie fruits extracts were concentration dependent, the higher the concentration of components in extract, the higher percentage of DPPH radicals was scavenged.

Oxygen radical absorbance capacity is used very often as a universal measurement of total antioxidant capacity when measured for hydrophilic and lipophilic compounds (Cao et al., 1993). In the case of this paper we measured only hydrophilic antioxidants because fruits generally contain trace amounts of lipids. The ORAC values for fruit extracts are presented in Table 3 , and the total antioxidant capacity varied from 0.16 to $7.99 \mathrm{mM} \mathrm{TE} / \mathrm{g}$ DM. Wild rose with the highest phenolics content also have the highest ORAC value. Elderberry extract had second in value ORAC at $1.31 \mathrm{mM} \mathrm{TE} / \mathrm{g}$ DM after RW comparable to AMA and HA (Table 3). Whereas BB, ER had the lowest value for this parameter among all fruits analysed
(Table 3). Wu et al. (2004) reported total antioxidant capacity in elderberry at the level of $0.147 \mathrm{mM} \mathrm{TE} / \mathrm{g}$ of fresh weight, which was significantly higher than in analyzed gooseberries as well as in black currants cultivars. Chokecherry extracts revealed ORAC values in methanol and acetone extracts at 480 and 214 $\mathrm{mg} \mathrm{TE} / 100 \mathrm{~g}$ fresh weight, respectively (Hosseinian et al., 2007). Coefficient of regression the total content of phenolics and flavonoids and ORAC was above $90 \%$, indicating very good relation between those parameters. These regression data further indicate that flavonoids are more efficient radical scavengers than all phenolics together. It is most likely that good relationship between ORAC and TP and TF in analysed samples is affected by similar profile of the phytochemicals present in those fruits. However, different types of phenolic compounds may contribute differently to total antioxidant capacity for a given food (Wu et al., 2004). Poor relationship found between total anthocyanins and ORAC indicates that those compounds were not efficient radical scavengers (Data not included). However, Wu et al. (2004) reported that in berries the best relationship was observed between ORAC and total phenolics $\left(R^{2}=0.96\right)$, followed by ORAC versus total anthocyanins.

In the $\beta$-carotene/linoleic acid model, this pigment undergoes rapid discolouration in the presence of linoleic acid radicals when an antioxidant is not present. 
As the highly unsaturated $\beta$-carotene chain is losing its conjugated configuration, its molecule change into colorless compound. Presence of phenolics from wild fruits extracts can hinder the $\beta$-carotene discolouration by scavenging the linoleate and other free radicals formed in the system (Amarowicz et al., 2004). The antioxidant activity of prairie fruits extracts as measured by extend of $\beta$-carotene bleaching in Figure 1 is presented. Antioxidative activity was observed in all methanolic extracts of fruits analysed. American mountain ash extract showed the highest antioxidant activity of 47.9 and $28.6 \%$ after 60 and $120 \mathrm{~min}$, respectively, while chokecherry the lowest at $16.1 \%$ and $7.4 \%$. Although RW extract had the highest total phenolics content, its antioxidant activity towards linoleic radicals was comparable to buffaloberry which had six times lower amount of phenolic compounds (Table 1, Fig. 1). This indicates that not only phenolics but other compounds such as vitamin $\mathrm{C}$ also contributed to scavenging activity (Karadeniz et al., 2005). Velioglu et al. (1998) found good relationship between the total phenolics and antioxidant activity for flaxseed and cereals, but not for the anthocyanin rich fruits and medicinal plants, suggested that besides phenolic compounds, other factors can play important role in antioxidant activity.

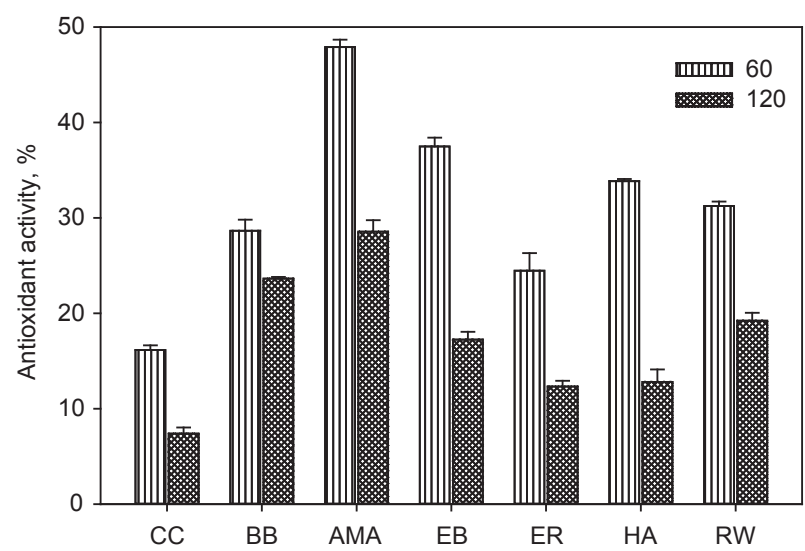

Fig. 1. Antioxidant activity of prairie fruits extracts as measured by bleaching $\beta$-carotene/linoleic acid system. Antioxidant activity expressed as the percent inhibition of $\beta$-carotene bleaching by oxidized linoleic acid, based on changes in absorbance at 60 and $120 \mathrm{~min}$. For sample abbreviation see Table 1
The antioxidative properties of prairie fruit extracts were assessed by measuring their antioxidative potential when applied to canola oil during accelerated storage and results are presented in Figure 2. All

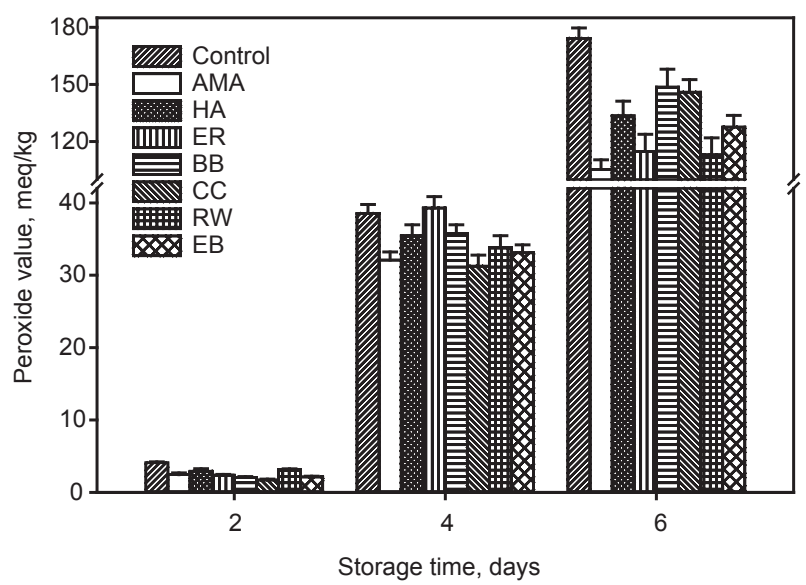

Fig. 2. Antioxidative effect of prairie fruits extracts in bulk canola oil as measured by Schaal Oven Test. For sample abbreviation see Table 1

extracts when applied at $800 \mathrm{ppm}$, showed ability to inhibit oxidation of canola oil. In SOT test the most effective was American mountain ash extract. Peroxide value of canola oil stored with it at the sixth day of storage was 39\% lower than for reference oil. In the case of European rowan and wild rose extracts PV was lower by 34 and $35 \%$, respectively compared to oil without additives. Albeit, CC and BB extracts had 3 times more of phenolic compounds than ER, nevertheless PV were only 16 and $15 \%$ lower compare to control, respectively. However, the inhibition of oxidative degradation was not as dramatic as could be predicted from scavenging activity discussed above, two factors need to be taken into account: (1) probably higher amount added may be more efficient; (2) solubility in oil and distribution may also be a factor in activity. Although the efficiency of antioxidant increases when the amount of compounds increased, natural antioxidants are recognized as less active and their activity depends very much on present synergists, both in extracts and in the system where they work (Evans, 1997). As the peroxide values indicate, antioxidant 
activity of prairie fruit is not simply related to the total phenolic components content. Possible synergism between different antioxidants is well established, mainly between flavonoids and tocopherols, ascorbyl palmitate and citric acid, and this partially explain higher antioxidant activity of AMA as well as ER extracts, which has higher percentage of total flavonoids than other samples (Rizner et al., 2000).

\section{CONCLUSION}

In conclusion, prairie fruits extracts are a rich source of phenolic compounds. The phenolics concentration varied considerably within prairie fruits from 39.6 to $656.4 \mathrm{mg} \mathrm{GEA} / \mathrm{g}$ extract, with wild rose (RW) being the richest. This also poses a high antioxidant capacity, which was confirmed by assessment with different type of radicals employed. The phenolics content, particularly flavonoids, correlated well with high antioxidant capacity of analyzed samples, especially with ORAC. In general, native rose, followed by American mountain ash demonstrated the highest antioxidant capacity among prairie fruits. This study suggests that prairie fruits can be a good source of natural antioxidants for food and pharmaceutical applications.

\section{REFERENCES}

Abuja, P. M., Murkovic, M., Pfannhauser, W. (1998). Antioxidant and prooxidant activities of elderberry (Sambucus nigra) extract in low-density lipoprotein oxidation. J. Agric. Food Chem., 46, 4091-4096.

Acuna, N. M., Atha, D. E., Ma, J., Nee, M. H., Kennelly, E. J. (2002). Antioxidant capacity of ten edible North American plants. Phytother. Res., 16, 63-65.

Amarowicz, R., Pegg, R. B., Rahimi-Moghaddam, P., Barl, B., Weil, J. A. (2004). Free-radical scavenging capacity and antioxidant activity of selected plant species from Canadian prairies. Food Chem., 84, 551-562.

Anwar, F., Przybylski, R., Rudzińska, M., Gruczyńska, E., Bain, J. (2008). Fatty acid, tocopherol and sterol compositions of Canadian prairie fruit seed lipids. J. Am. Oil Chem. Soc., 85, 953-959.

Bakowska-Barczak A. M., Kolodziejczyk, P. (2008). Evaluation of Saskatoon berry (Amelanchier alnifolia Nutt.) cultivars for their polyphenol content, antioxidant properties, and storage stability. J. Agric. Food Chem., 56, 9933-9940.
Bakowska-Barczak A. M., Marianchuk, M., Kolodziejczyk, P. (2007). Survey of bioactive components in Western Canadian berries. Can. J. Physiol. Pharmacol., 85, 1139-1152.

Bronnum-Hansen, K., Hansen, S. H. (1983). High-performance liquid chromatographic separation of anthocyanins of Sambucus nigra L. J. Chrom., 262, 385-392.

Cao, G., Alessio, H. M., Culter, R. G. (1993). Oxygen-radical absorbance capacity assay for antioxidants. Free Radical Biol. Med., 14, 303-311.

Cao, G., Sofic, E., Prior, R. L. (1997). Antioxidant and prooxidant behaviour of flavonoids: structure-activity relationships. Free Radical Biol. Med., 22, 749-760.

Cao, G.Y., Feng, X.Y., Qin, X.Q. (1995). Analysis of the chemical constituents of hawthorn fruits and their quality evaluation. Acta Pharm. Sin., 30, 138-143.

Chu, C. Y., Lee, M. J., Liao, C. L., Lin, W. L., Yin, Y. F., Tseng, T. H. (2003). Inhibitory effect of hot-water extract from dried fruit of Crataegus pinnatifida on lowdensity lipoprotein (LDL) oxidation in cell and cell-free systems. J. Agric. Food Chem., 51, 7583-7588.

Dewanto, V., Wu, X., Adom, K. K., Liu, R. H. (2002). Thermal processing enhances the nutritional value of tomatoes by increasing total antioxidant activity. J. Agric. Food Chem., 50, 3010-3014.

Ercisli, S., Esitken, A. (2004). Fruit characteristics of native rose hip (Rosa spp.) selections from the Erzurum province of Turkey. New Zeal. J. Crop. Hort., 32, 51-53.

Evans, R. J. (1997). Optimizing lipid stability with natural antioxidants. In F. Shahidi (Ed.), Natural antioxidants (pp. 224-244). Champaign, IL (USA): AOCS Press.

Frankel, E. N., Waterhouse, A. L., Teissedre, P. L. (1995). Principal phenolic phytochemicals in selected California wines and their antioxidant activity in inhibiting oxidation of human low-density lipoproteins. J. Agric. Food Chem., 43, 890-894.

Gil-Izquierdo, A., Mellenthin, A. (2001). Identification and quantitation of flavonols in rowanberry (Sorbus aucuparia L.) juice. Eur. Food Res. Technol., 213, 12-17.

Hosseinian, F. S., Li, W., Hydamaka, A. W., Tsopmo, A., Lowry, L., Friel, J., Beta, T. (2007). Proanthocyanidin profile and ORAC values of Manitoba berries, chokecherries and seabuckthorn. J. Agric. Food Chem., 55, 6970-6976.

Huang, D., Ou, B., Prior, R. L. (2005). The chemistry behind antioxidant capacity assays. J. Agric. Food Chem., $53,1841-1856$.

Hukkanen, A. T., Polonen, S. S., Karenlampi, S. O., Kokko, H. I. (2006). Antioxidant capacity and phenolic content of sweet rowanberries. J. Agric. Food Chem., 54, 112-119. 
Kahkonen, M. P., Hopia, A. I., Heinonen, M. (2001). Berry phenolics and their antioxidant activity. J. Agric. Food Chem., 49, 4076-4082.

Karadeniz, F., Burdurlu, H. S., Koca, N., Soyer, Y. (2005). Antioxidant activity of selected fruits and vegetables grown in Turkey. J. Agric. Food Chem., 29, 297-303.

Kirakosyan, A., Seymour, E., Kaufman, P. B., Warber, S., Bolling, S., Chang, S. C. (2003). Antioxidant capacity of polyphenolic extracts from leaves of Crataegus laevigate and Crataegus monogyna (Hawthorn) subjected to drought and cold stress. J. Agric. Food Chem., 51, 3973-3976.

Lohachoompol, V., Srzednicki, G., Craske, J. (2004). The change of total anthocyanins in blueberries and their antioxidant effect after drying and freezing. J. Biomed. Biotechnol., 5, 248-252.

Loliger, J. (1991). Use of antioxidants in food. In O. I. Arouma, B. Halliwell (Eds.), Free radicals and food additives (pp. 121-150). London, UK: Taylor and Francis.

Pratt, D. E. (1992). Natural antioxidants from plant material. In M. T. Huang, C. T. Ho, C. Y. Lee (Eds.), Phenolic compounds in food and their effects on health II. Antioxidants and cancer prevention (pp. 54-71). Washington: American Chemical Society, ACS Symposium Series 507.

Rice-Evans, C. A., Miller, N. J., Paganga, G. (1996). Structure-antioxidant activity relationships of flavonoids and phenolic acids. Free Radical Biol. Med., 20, 933-956.

Rice-Evans, C. A., Miller, N. J., Paganga, G. (1997). Antioxidant properties of phenolic compounds. Trends Plant Sci., 4, 152-159.

Rizner Hras, A., Hadolin, M., Knez, Z., Bauman, D. (2000). Comparison of antioxidative and synergistic effects of rosemary extraction with a-tocopherol, ascorbyl palmitate and citric acid in sunflower oil. Food Chem., 71, 229-233.

Sanchez-Moreno C., Larrauri, J. A., Saura-Calixto, F. A. (1998). A procedure to measure the antiradical efficiency of polyphenols. J. Sci. Food Agric., 76, 270-276.

Shantha, N. C., Decker, E. A. (1994). Rapid, sensitive, iron-based spectrophotometric methods for determination of peroxide values of food lipids. J. AOAC Int., 77, 421-424.

Received - Przyjęto: 25.05.2015

For citation - Do cytowania
Skerget, M., Kotnik, P., Hadolin, M., Rizner Hras, A., Simonic, M., Knez, Z. (2005). Phenols, proanthocyanidins, flavones and flavonols in some plant materials and their antioxidant activities. Food Chem., 89, 191-198.

Szydłowska-Czerniak, A., Karlovits, G., Dianoczki, C., Recseg, K., Szłyk, E. (2008). Comparison of two analytical methods for assesing antioxidant capacity of rapeseed and olive oil. J. Am. Oil Chem. Soc., 85, 141-149.

Tadic, V. M., Dobric, S., Markovic, G. M., Dordevic, S. M., Arsic, I. A., Menkovic, N. R., Stevic, T. (2008). Antiinflammatory, gastroprotective, free-radical-scavenging, and antimicrobial activities of hawthorn berries ethanol extract. J. Agric. Food Chem., 56, 7700-7709.

Taga, M. S., Miller, E. E., Pratt, D. E. (1984). Chia seeds as a source of natural lipid antioxidants. J. Am. Oil Chem. Soc., 61, 928-931.

Velioglu, Y. S., Mazza, G., Gao, L., Oomah, B. D. (1998). Antioxidant activity and total phenolics in selected fruits, vegetables and grain products. J. Agric. Food Chem., 46, 4113-4117.

Verhagen, J. V., Haenen, G. R. M. M., Bast, A. (1996). Nitric oxide radical scavenging by wines. J. Agric. Food Chem., 44, 3733-3734.

Villano, D., Fernandez-Pachon, M. S., Troncoso, A. M., Garcia-Parrilla, M. C. (2005). Comparison of antioxidant activity of wine phenolic compounds and metabolites in vitro. Anal. Chim. Acta, 538, 391-398.

Wanasundara, U. N., Shahidi, F. (1998). Antioxidant and pro-oxidant activity of green tea extracts in marine oils. Food Chem., 63, 335-342.

Wu, X., Prior, R. L. (2005). Systematic identification and characterization of anthocyanins by HPLC-ESI-MS/MS in common foods in the United States: fruits and berries. J. Agric. Food Chem., 53, 2589-2599.

Wu, X., Gu, L., Prior, R. L., McKay, S. (2004). Characterization of anthocyanins and proanthocyanidins in some cultivars of Ribes, Aronia and Sambucus and their antioxidant capacity. J. Agric. Food Chem., 52, 7846-7856.

Yi, O., Jovel, E. M., Towers, G. H. N., Wahabe, T. R., Cho, D. (2007). Antioxidant and antimicrobial activities of native Rosa sp. from British Columbia, Canada. Int. J. Food Sci. Nutr., 58, 178-189.

Accepted for print - Zaakceptowano do druku: 3.09.2015

Klensporf-Pawlik, D., Przybylski, R. (2015). Antioxidant activity of selected wild Canadian prairie fruits. Acta Sci. Pol. Technol. Aliment., 14(4), 357-366. DOI: 10.17306/J.AFS.2015.4.35 